\title{
Sinorhizobium meliloti Chemotaxis to Multiple Amino Acids Is Mediated by the Chemoreceptor McpU
}

\author{
Benjamin A. Webb, ${ }^{1}$ K. Karl Compton, ${ }^{1}$ Julia S. Martin del Campo, ${ }^{2}$ Doris Taylor, ${ }^{1}$ Pablo Sobrado, ${ }^{2}$ and \\ Birgit E. Scharf ${ }^{1, \dagger}$ \\ ${ }^{1}$ Virginia Tech, Department of Biological Sciences, Life Sciences I, Blacksburg, VA 24061, U.S.A.; and ${ }^{2}$ Virginia Tech, \\ Department of Biochemistry, Fralin Life Science Institute
}

Accepted 14 June 2017.

\begin{abstract}
The legume symbiont Sinorhizobium meliloti is chemoattracted to compounds exuded by germinating seeds of its host alfalfa. This response is mainly mediated by the $S$. meliloti chemoreceptor McpU. McpU also has a prominent contribution in sensing a synthetic amino acid (aa) mixture mimicking the amounts and composition observed in seed exudate. Here, we used the hydrogel capillary assay to quantify chemotactic responses of $S$. meliloti to individual aa exuded by germinating alfalfa seeds and to define the role of McpU in this behavior. $S$. meliloti exhibited positive chemotaxis responses to all proteinogenic aa, except for aspartate, and to citrulline, cystine, gamma-aminobutyric acid, and ornithine. Wild-type responses were diverse in intensity, while a strain lacking $m c p U$ displayed strongly diminished responses. Differential scanning fluorimetry demonstrated interaction of the purified periplasmic region of $\mathrm{McpU}$ (McpU-PR) with the aa, except glutamate and aspartate. We additionally tested organic acids and sugars, but there were no significant interactions with the McpU ligand-binding domain, except for citrate. Using ligand displacement, we confirmed the interaction of McpU-PR with aa representing strong and weak attractants. Our results show that $S$. meliloti McpU is a broad-range aa receptor mediating differential responses to individual attractants, which does not bind negatively charged aa.
\end{abstract}

Soil-dwelling bacteria from the Rhizobiaceae family form a species-specific symbiosis with their legume hosts that is characterized by the formation of a plant organ known as a nodule (Cooper 2007; Jones et al. 2007; Suzaki et al. 2015). In developing nodules, bacteria undergo metamorphosis into bacteroids, which fix atmospheric nitrogen into ammonium. This form of nitrogen is utilized by the plant to aid in prolific growth (Hirsch et al. 2001; Jones et al. 2007). Bacterial chemotaxis precedes symbiosis and enables rhizobia to actively swim toward and accumulate in the host spermosphere and rhizosphere by responding to hostreleased compounds (Ames and Bergman 1981; Bergman et al. 1988; Caetano-Anollés et al. 1988; Dharmatilake and Bauer 1992; Malek 1989; Scharf et al. 2016; Soby and Bergman 1983; Uren 2000). In particular, rhizobial motility and chemotaxis have been proven to enhance successful symbiotic interactions of Bradyhizobium japonicum, Rhizobium leguminosarum, Rhizobium trifolii, and Sinorhizobium meliloti, with soybean, pea, clover,

Current address for Doris Taylor: Department of Biochemistry and Molecular Biology, Baylor University, Houston, TX 77030, U.S.A.

${ }^{\dagger}$ Corresponding author: B. E. Scharf; E-mail: bscharf@vt.edu

(c) 2017 The American Phytopathological Society and alfalfa, respectively (Althabegoiti et al. 2008; Ames and Bergman 1981; Caetano-Anollés et al. 1988; Mellor et al. 1987; Miller et al. 2007).

A germinating seed exudes a multitude of compounds into the soil, creating a unique and species-specific spermosphere (Nelson 2004). The complex molecular composition of seed exudates comprises amino acids (aa), sugars, lipids, phenolics, proteins, and other metabolites (Barbour et al. 1991; Nelson 2004; Webb et al. 2014). Positive chemotactic responses to host seed exudates were described for Bradyhizobium japonicum, R. leguminosarum, and S. meliloti (Barbour et al. 1991; Gaworzewska and Carlile 1982; Webb et al. 2014). However, the heterogeneous nature of exudates hampers the identification of individual molecules responsible for the chemotactic responses.

Preceding work characterized the response of $S$. meliloti to the exudate of germinating alfalfa seeds and identified that host seed-derived aa contribute to $23 \%$ of this response (Webb et al. 2016). S. meliloti uses eight chemoreceptors, namely seven methyl-accepting chemotaxis proteins (McpT to McpZ) and one internal chemotaxis protein (IcpA), for chemotaxis (Meier et al. 2007). Each chemoreceptor is composed of a variable sensing domain and a highly conserved signaling domain. A variety of molecules have been identified to serve as chemoattractants, including aa, organic acids, and sugars, but the functions of the corresponding chemoreceptors are mostly unknown (Meier et al. 2007).

We previously presented that McpU senses proline (pro) via tandem cache domains located in its periplasmic region (Anantharaman and Aravind 2000; Webb et al. 2014). The domain architecture of McpU is depicted in Figure 1. Moreover, $\mathrm{McpU}$ is the most important chemoreceptor for host exudate and aa recognition (Webb et al. 2016). Homology modeling of the periplasmic region of McpU (McpU-PR), with the crystal structure of Vibrio cholerae McpN as the template, identified the ligand-binding site and, specifically, two conserved aspartate residues (asp-155 and asp-182) of the N-terminal cache domain to be involved in ligand sensing. The prediction was supported by chemotaxis behavioral assays of single point mutants and in vitro binding analysis of purified mutant variant proteins (Webb et al. 2014). The recognized motif, also known as a double PhoQ-DcuS-CitA (PDC) domain, recognizes aa directly as well as indirectly through $\mathrm{ABC}$ transport-binding lipoproteins (Anantharaman and Aravind 2000; Glekas et al. 2012; McKellar et al. 2015; Reyes-Darias et al. 2015; Ulrich and Zhulin 2005; Webb et al. 2014).

In this study, we characterized the strength and temporal reaction profile of all proteinogenic aa as well as to citrulline (cit), cystine (c-c), gamma-aminobutyric acid (gaba), and ornithine (orn) in S. meliloti chemotaxis, as they are present in alfalfa seed 
exudates. Since the pro sensor McpU is the most important chemoreceptor for host exudate and aa recognition, we elucidated its role in aa sensing, using quantitative in vivo chemotaxis assays and in vitro binding assays with McpU-PR.

\section{RESULTS}

\section{Chemotaxis of $S$. meliloti wild type and the mcpU deletion strain toward aa.}

Since host seed-derived aa are contributing to $23 \%$ of the chemotactic response to whole-seed exudates (Webb et al. 2016), we determined the chemotactic strength of individual proteinogenic aa, cit, c-c, gaba, and orn in $S$. meliloti chemotaxis. We also tested the response of the $m c p U$ deletion strain, because experimental and bioinformatics evidence suggested that McpU serves as a general aa sensor (Webb et al. 2014, 2016). Chemotactic responses of both strains were observed in a modified hydrogel capillary assay, which enables quantitative time-course assessments (Webb et al. 2016). Each capillary contained a hydrogel that was equilibrated with a $1-\mathrm{mM}$ compound dissolved in rhizobial basal medium (RB). Cells exhibiting positive chemotaxis accumulated at the mouth of the capillary, whereas no accumulation was observed for the control capillary with RB or for a chemotaxis-negative strain (che) (Webb et al. 2016; data not shown). Photographs were taken near the mouth of the capillary every 4 min under a pseudo-dark field, and the pixel intensity in front of the capillary, correlating with the number of cells, was quantified as described (Webb et al. 2016). The ability to observe a quantitative temporal response can reveal additional information about sensitivity and response time through the documentation of a complete time course.

An initial assessment of response sensitivity was gathered for 24 aa (Fig. 2). The wild-type strain responded to all aa, except aspartic acid (asp), but with different intensities and time courses. The strongest wild-type response occurred after exposure to arginine (arg) for $16 \mathrm{~min}$, and all responses depicted in Figure 2 were normalized to this value. Response curves categorized from strongest to weakest (Fig. 2A to $\mathrm{H}$, respectively). Peak responses of wild type and the mcpU deletion strain are compared in Figure 3. The strongest peak responses to alanine (ala), arg, histidine (his), leucine (leu), phenylalanine (phe), threonine (thr), and tryptophan (trp) ranged from 0.50 to 1.00 . Responses to isoleucine (ile), lysine (lys), methionine (met), pro, serine (ser), and tyrosine (tyr) are medium to strong, ranging from 0.38 to 0.50 . The third group comprises weak to medium responses to asparagine (asn), cit, glycine (gly), orn, tyr, and valine (val). The last group contains weak responses to c-c, cys, gaba, glutamine (gln), and glutamic acid (glu), and no response to asp. The response of the $m c p U$ deletion strain to all aa was decreased substantially as compared with the wild-type response. In particular, responses to arg, cit, cys, c-c, gaba, glu, lys, orn, phe, and ser fell within the region of no response (gray box in Figure 2A to $\mathrm{H})$. Responses to the remaining aa stayed much lower than that of wild type. We also noticed that response curves were differently shaped (Fig. 2). Wild-type responses to gaba, lys, pro, and ser peaked relatively early between 8 and $12 \mathrm{~min}$, while responses to ala, arg, asn, c-c, cit, gaba, gln, glu, gly, leu, thr, and val peaked at around 12 to $18 \mathrm{~min}$, and responses to cys, his, ile, met, orn, and phe gradually increased to a plateau response at around $25 \mathrm{~min}$. Interestingly, the response to trp and tyr increased steadily during the 40-min observation period. Upon closer microscopic examination, it was noticed that declining responses toward the end of the observation period are due to the dissemination of cells away from the capillary. This response can be explained by attractant depletion due to diffusion from the capillaries into the bacterial ponds, bacterial metabolism of the attractant, or production of repellent.

To obtain quantitative and statistically validated datasets, ten representative aa were selected for detailed analyses, based on strength of response, shape of response time curve, and nature of aa side chain. We also extended the observation time, because responses to certain aa were still increasing after $40 \mathrm{~min}$. All data were normalized to the highest wild-type response observed during these assays. Overall, general trends for the wildtype response observed during the initial screening (Fig. 2) were confirmed; however, certain rankings changed. For instance, while arg elicited the greatest response in our initial screen, phe was found to elicit the strongest response after averaging three datasets. Generally, arg, phe, thr, and trp elicited the greatest responses (60 to $85 \%)$, followed by his, leu, met, and pro (30 to $50 \%)$. Glu was confirmed as a very weak attractant (Fig. 4C). In addition, the mcpU deletion strain exhibited no response to these aa, except for a very weak response (10 to $15 \%$ ) to leu and thr (Fig. $4 \mathrm{C}$ and E). It was also statistically validated that asp is not recognized as chemoattractant by $S$. meliloti under these assay conditions (Fig. 4E). Three aa, namely arg, pro, and thr, exhibited a fast increase and a clear peak response at around $12 \mathrm{~min}$. This result is in agreement with the preliminary individual biological replicate (Fig. 2). The response curves for leu and met reached a steady plateau at around $15 \mathrm{~min}$, also confirming the original dataset (Fig. 4D and E). Most interestingly, responses to phe and trp displayed very broad response curves, with maxima at 34 and $49 \mathrm{~min}$, respectively (Fig. 4A and B). Taken together, these results establish that all aa but asp are chemoattractants for S. meliloti, with distinct responses to individual compounds. Furthermore, we demonstrated that aa chemotaxis is mediated through McpU.

\section{Thermal denaturation of McpU-PR with aa.}

To monitor direct interactions of aa with $\mathrm{McpU}$, we performed differential scanning fluorimetry (DSF) with the isolated McpU-PR and a single aa variant, McpU-PR ${ }^{\mathrm{D} 182 \mathrm{E}}$, which is strongly reduced in function. Homology modeling predicted the involvement of asp-182 together with asp-155 in ligand coordination, by forming hydrogen bonds between their oxygen atoms and the amino group of the ligand. This prediction was experimentally supported for the binding of pro to $\mathrm{McpU}$ in vivo and in vitro (Webb et al. 2014). Since ligand coordination

TM1 TM2

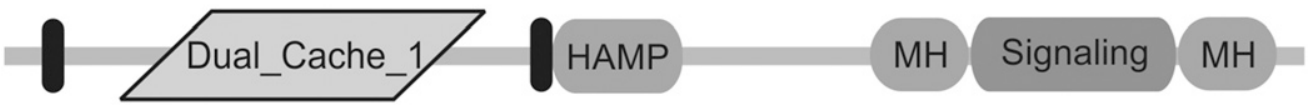

Fig. 1. Domain architecture of Sinorhizobium meliloti McpU, according to the Pfam database. Cache is an acronym formed from the names of proteins in which these signaling domains were recognized (animal $\mathrm{Ca}^{2+}$ channel subunits and prokaryotic chemotaxis receptors) (Anantharaman and Aravind 2000); TM1 and TM2 are transmembrane regions 1 and 2; HAMP is the conserved signal transduction domain in histidine kinases, adenylyl cyclases, methyl-accepting chemotaxis proteins, and phosphatases (Aravind and Ponting 1999); MH is a methyl-accepting helix; signaling is the methyl-accepting chemotaxis protein signaling domain and interaction site for CheA and CheW. 
involves the amino group of aa, we hypothesize that this variant protein can serve as a negative control for ligand binding. Thermal unfolding of both proteins, wild-type and mutant McpU-PR, in the presence of the fluorescent dye SYPRO orange and individual aa was monitored. A resulting sigmoidal melting curve yields an inflection point, which denotes the melting temperature $\left(\mathrm{T}_{\mathrm{m}}\right)$ of half the protein population. In the presence of stabilizing ligands, the $\mathrm{T}_{\mathrm{m}}$ shifts to higher temperatures (Niesen et al. 2007). McpU-PR and McpU-PR ${ }^{\mathrm{D} 182 \mathrm{E}}$ in the absence of ligand yielded an average $\mathrm{T}_{\mathrm{m}}$ of 36 and $34^{\circ} \mathrm{C}$,
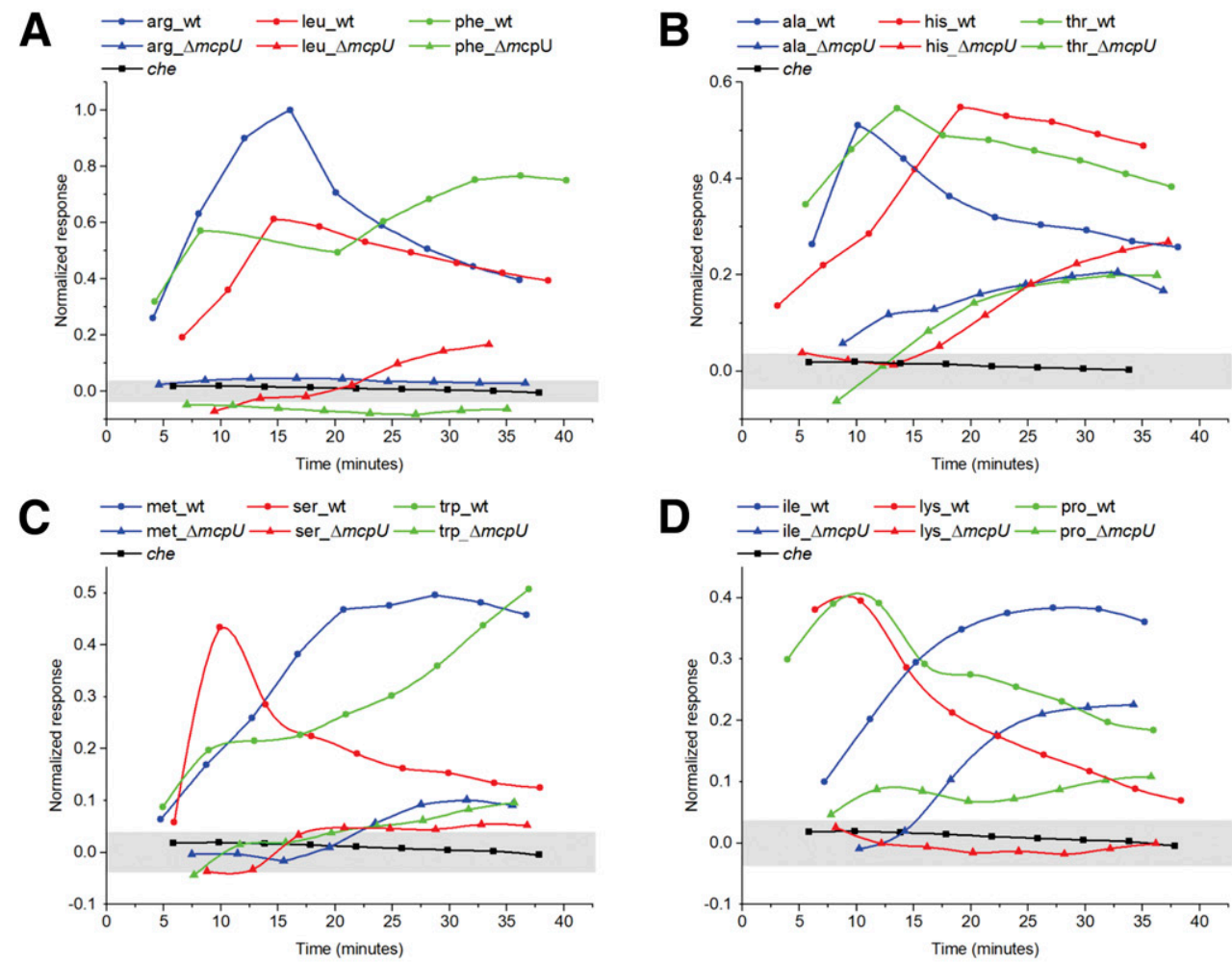

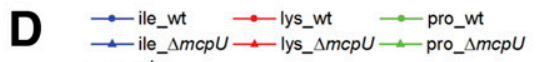
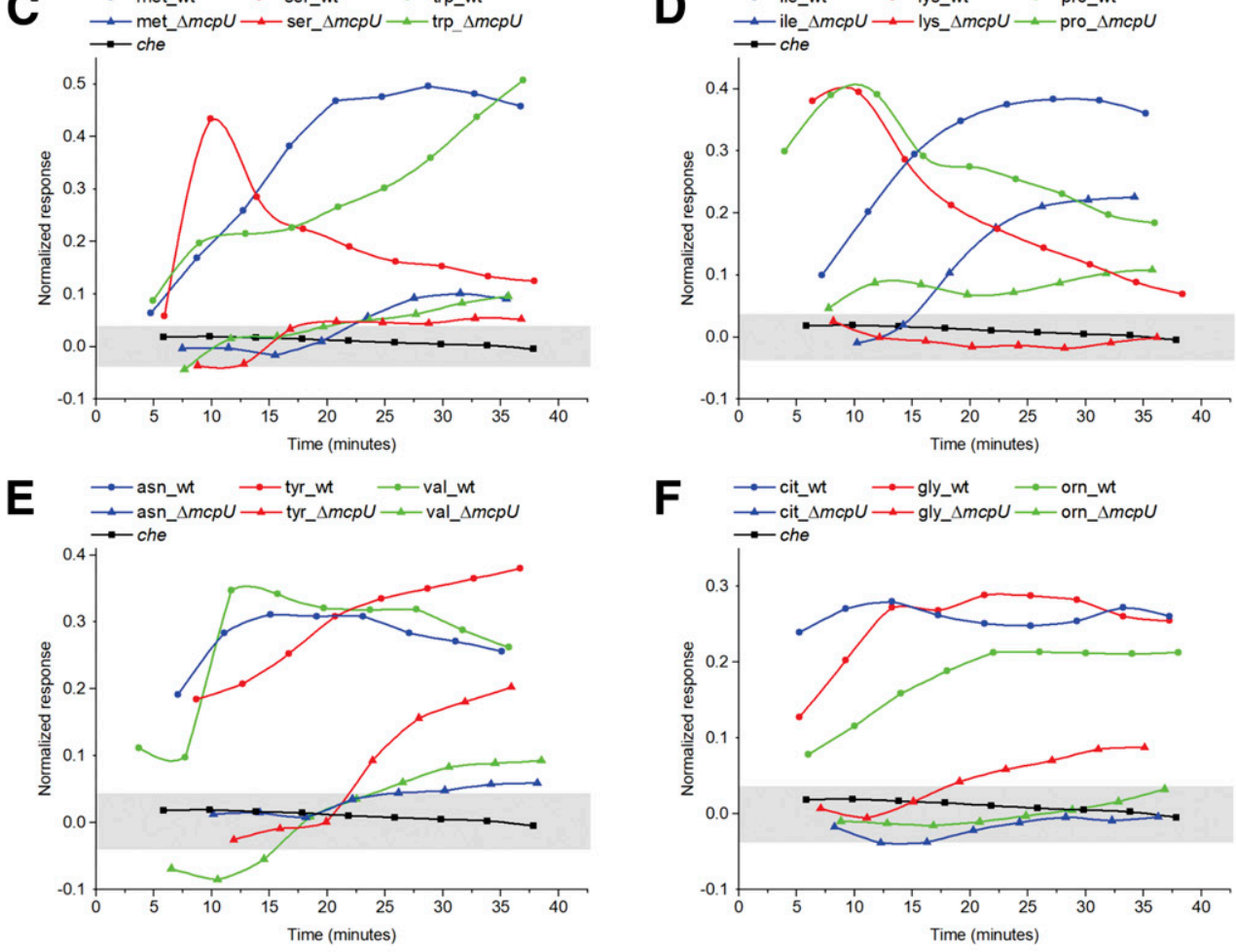

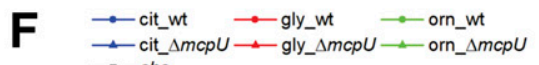
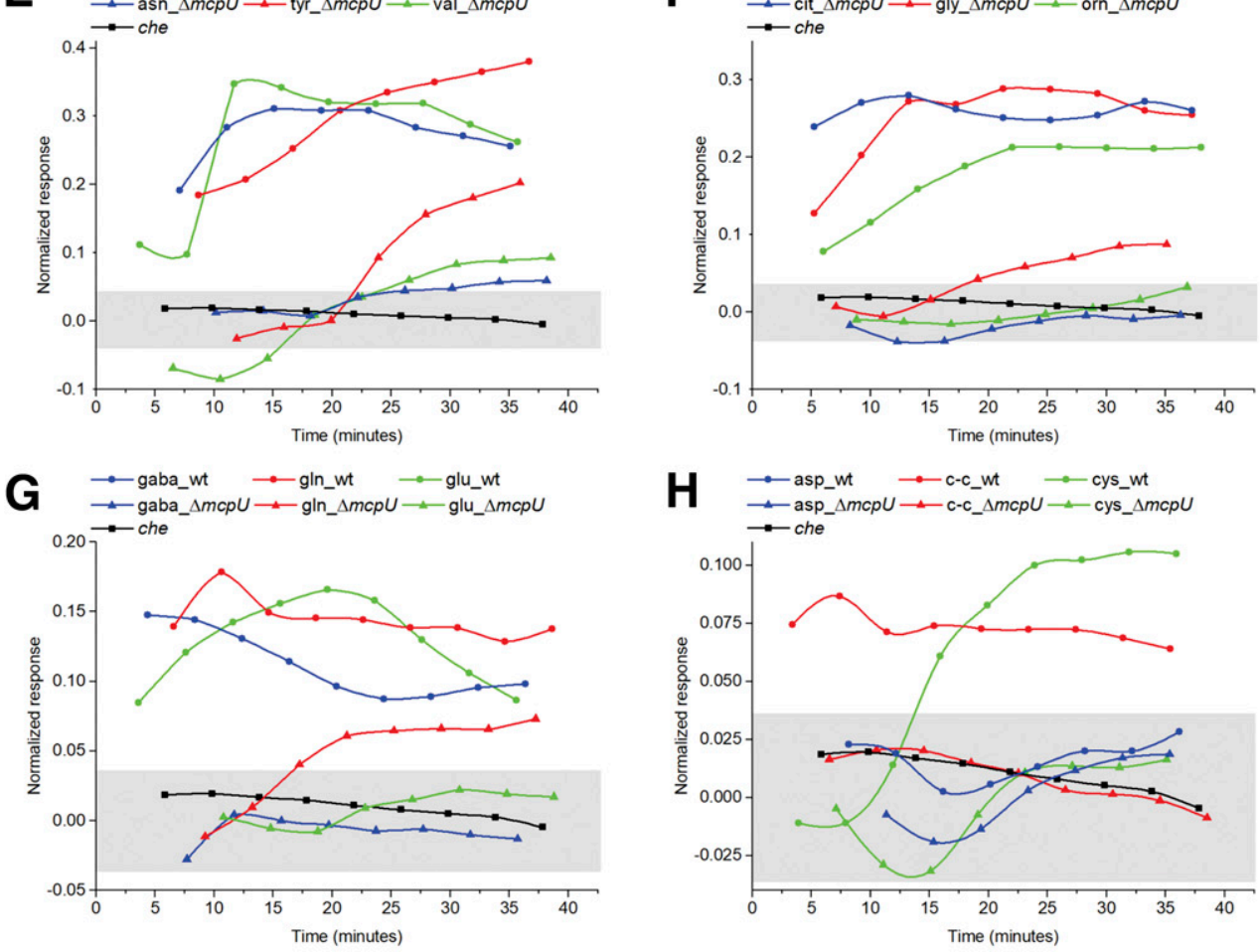

Fig. 2. Chemotaxis responses of Sinorhizobium meliloti wild type and the $\Delta m c p U$ strain to amino acids (aa) at a concentration of 1 mM in the hydrogel capillary assay. Images were taken under a pseudo-dark field every 4 min, and the pixel intensities at the mouth of the capillaries were quantified and normalized to the maximum response observed (wild-type response to arginine [arg] at 16 min). A to $\mathbf{H}$, Wild-type $(\mathbf{O})$ and $\Delta m c p U$ ( $\mathbf{\square})$ responses to each aa are color-coded and grouped from the highest to the weakest response. The response of the che strain (black squares and lines) to arg is given for comparison. The gray box in each graph represents the region of no response as determined by fluctuations in background pixel intensity $( \pm 0.036)$. 
respectively, which were subtracted from the $T_{m}$ determined in the presence of an added compound. Background fluctuations in fluorescence in reactions with McpU-PR and McpU-PR ${ }^{\mathrm{D} 182 \mathrm{E}}$ in the absence of a compound were determined to be $\pm 1.5^{\circ} \mathrm{C}$ each. Four representative curves demonstrating the singlephase transition of the melting curves are given in Figure 5. Next, $T_{m}$ shifts were plotted against corresponding (Fig. 6). All aa except asp and glu shifted the $\mathrm{T}_{\mathrm{m}}$ of McpU-PR significantly above the background level, between 2.5 and $15.5^{\circ} \mathrm{C}$. In contrast, McpU-PR ${ }^{\mathrm{D} 182 \mathrm{E}}$ only experienced $\mathrm{T}_{\mathrm{m}}$ shifts slightly above background in the presence of cit, cys, pro, and trp. We also tested for the interactions of two nonmetabolizable analogs of arg and pro, namely canavanine and azetidine-2-carboxylate, which produced substantial $\mathrm{T}_{\mathrm{m}}$ shifts of 11.5 and $13.0^{\circ} \mathrm{C}$, respectively. Additional compounds tested for binding to McpUPR included six organic acids, three inorganic salts, and ten sugars and sugar derivatives, with corresponding $T_{m}$ shifts listed in Table 1. With the exception of citric acid, which produced a shift of $14.0^{\circ} \mathrm{C}$, none of the tested compounds produced a significant $\mathrm{T}_{\mathrm{m}}$ shift. Taken together, these results demonstrate that McpU-PR directly interacts with nonacidic aa and citric acid.

\section{Ligand displacement assays of McpU-PR with aa.}

To assess the correlation between strength of chemotactic response in vivo and binding affinity of McpU-PR to aa in vitro, we performed binding assays using centrifugal filter units and measured trp fluorescence of the flow-through. We tested McpU-PR with the strong attractant trp and performed ligand displacement assays with two strong attractants (arg and phe), a medium attractant (pro), a very weak attractant (glu), and with a nonattractant aa (asp). The titration of McpU-PR with trp yielded a $\mathrm{K}_{\mathrm{d}}$ (dissociation constant) of $34 \mu \mathrm{M}$ (Table 2). For the ligand displacement assays, we saturated the protein with trp and titrated with the other aa. The $\mathrm{K}_{\mathrm{d}}$ for phe and pro was determined to be 53 and $42 \mu \mathrm{M}$, respectively, while the $K_{d}$ of arg was $350 \mu \mathrm{M}$. No binding was observed for asp and glu (Table 2). The lack of binding for asp and glu was confirmed using isothermal titration calorimetry (data not shown). In conclusion, these data confirmed results gained from the DSF experiments, in particular, binding of phe, pro, and trp to McpU-PR and a lack of interaction with asp and glu. Furthermore, we can conclude that phe, pro, and trp bind with similar affinity to $\mathrm{McpU}$, while the interaction with arg is 10 -fold weaker.

\section{DISCUSSION}

Chemotaxis toward host seed- and root-exuded attractants is an important step in early host-microbe interaction (Scharf et al. 2016). Since $23 \%$ of the chemotactic response of $S$. meliloti RU11/001 to exudates from germinating alfalfa seeds is due to aa chemotaxis, we screened the chemotactic potency of 24 aa, using a recently developed hydrogel capillary assay (Webb et al. 2016), followed by quantitative time course assessments for 10 representative aa. While the $S$. meliloti wild-type response to a synthetic aa mixture peaked at $12 \mathrm{~min}$ (Webb et al. 2016), maxima for the reaction to individual aa in the quantitative assay varied greatly from 8 to 46 min (Fig. 4). This complex reaction pattern might stem from the diverse chemical nature of the aa side chains and molecule size, although no obvious correlation between hydrophobicity, charge, or diffusion coefficient was observed. Most notably, responses to arg and pro peaked early and rapidly leveled off to baseline response, whereas responses to phe and trp increased slowly with a broad plateau. However, it should be taken into account that the assays were all performed at the same aa concentrations of
$1 \mathrm{mM}$, which might not reflect optimal conditions for all aa. Relative strength of attraction was not related to the aa class, with arg, phe, pro, and trp as the strongest attractants being positively charged and hydrophobic, respectively. A comparable lack of correlation was reported for aa taxis in Escherichia coli and Bacillus subtilis (Glekas et al. 2012; Mesibov and Adler 1972). No clear relationship was seen between the strength of attraction and the amount exuded by germinating alfalfa seeds (Webb et al. 2016). For instance, the four aa exuded at the highest concentration $(>1.5 \mathrm{mM})$, i.e., ala, asn, gly, and val, elicited relative responses of 30 to $50 \%$, while the four aa eliciting the highest responses, i.e., arg, phe, thr, and trp, are exuded at 0.5 to 0.7 and $0.1 \mathrm{mM}$ for trp. However, chemoreceptors exhibit a very broad range of sensitivity (Bi and Lai 2015; Hazelbauer et al. 2008), which makes the approximately 10 -fold difference in exuded aa amounts negligible. S. meliloti RU11/001 chemoattraction to most aa is consistent with previous findings of the parental strain MVII-1, using traditional Adler capillary assays (Götz et al. 1982). Recognition and chemotaxis toward a broad range of aa enables $S$. meliloti to benefit from these carbon compounds as energy sources and host-plant signaling molecules. A strain lacking mcpU displayed no response to the majority of the aa in the hydrogel capillary assay (Figs. 2, 3, and 4). The weak responses toward leu and thr might suggest overlapping specificity of McpU with other chemoreceptors. Potential candidates are cache domain-bearing receptors, such as $\mathrm{McpX}$ and $\mathrm{McpV}$, or the hypothetical energy sensors IcpA and McpY (Meier et al. 2007).

Results from the thermal denaturation studies demonstrated direct interaction of McpU-PR with all aa except asp and glu. This finding is in agreement with the behavioral assays, which supports the hypothesis that $\mathrm{McpU}$ is a general aa sensor and that the chemotactic response is mediated through direct binding. The only exception is glu, which does not bind to McpU-PR in vitro but elicits a weak, McpU-dependent chemotaxis response. We hypothesize that chemotaxis toward glu is mediated through indirect binding to $\mathrm{McpU}$, analogous to McpC of Bacillus subtilis, which senses gln via binding of $\mathrm{GlnH}$, an $\mathrm{ABC}$ transport-binding lipoprotein (Glekas et al.

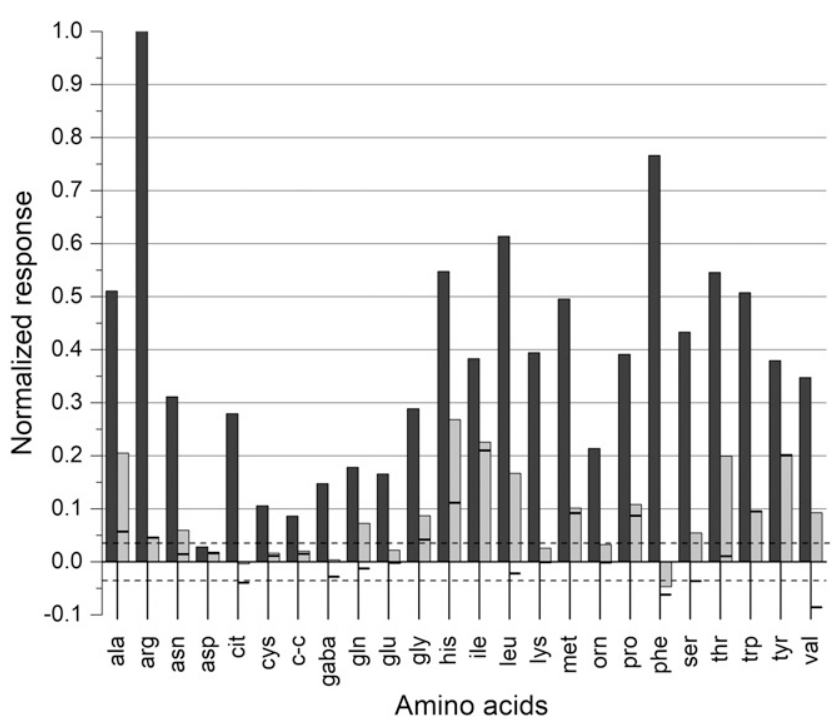

Fig. 3. Maximal peak responses of Sinorhizobium meliloti wild type (dark gray) and the $\Delta m c p U$ strain (light gray) to amino acids normalized to the maximum response to arginine at $16 \mathrm{~min}$. The horizontal lines in columns of the $\Delta m c p U$ strain reflect its response at the time of wild-type peak response. The dotted lines depict the region of no response. 
2012). S. meliloti possesses a general L-aa transporter system with broad specificity (Aap), and the solute binding protein AapJ is a potential candidate for mediating glu taxis (Dunn 2015). Previous work identified two conserved residues, asp-155 and asp-182, in the amino-proximal PDC domain of McpU as critical for pro binding (Webb et al. 2014). Using DSF, we showed that only three of the aa were able to exhibit weak interaction with the variant protein $\mathrm{McpU}-\mathrm{PR}^{\mathrm{D} 182 \mathrm{E}}$ (Fig. 5).
A

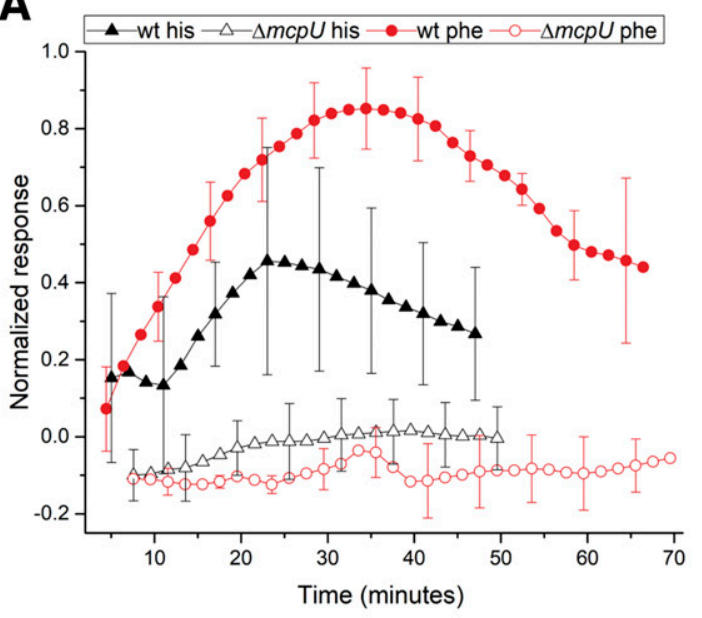

C

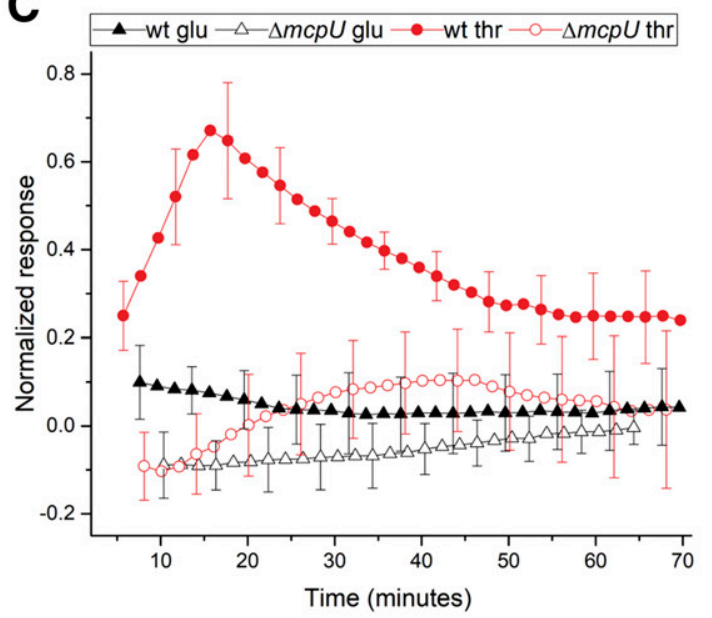

B
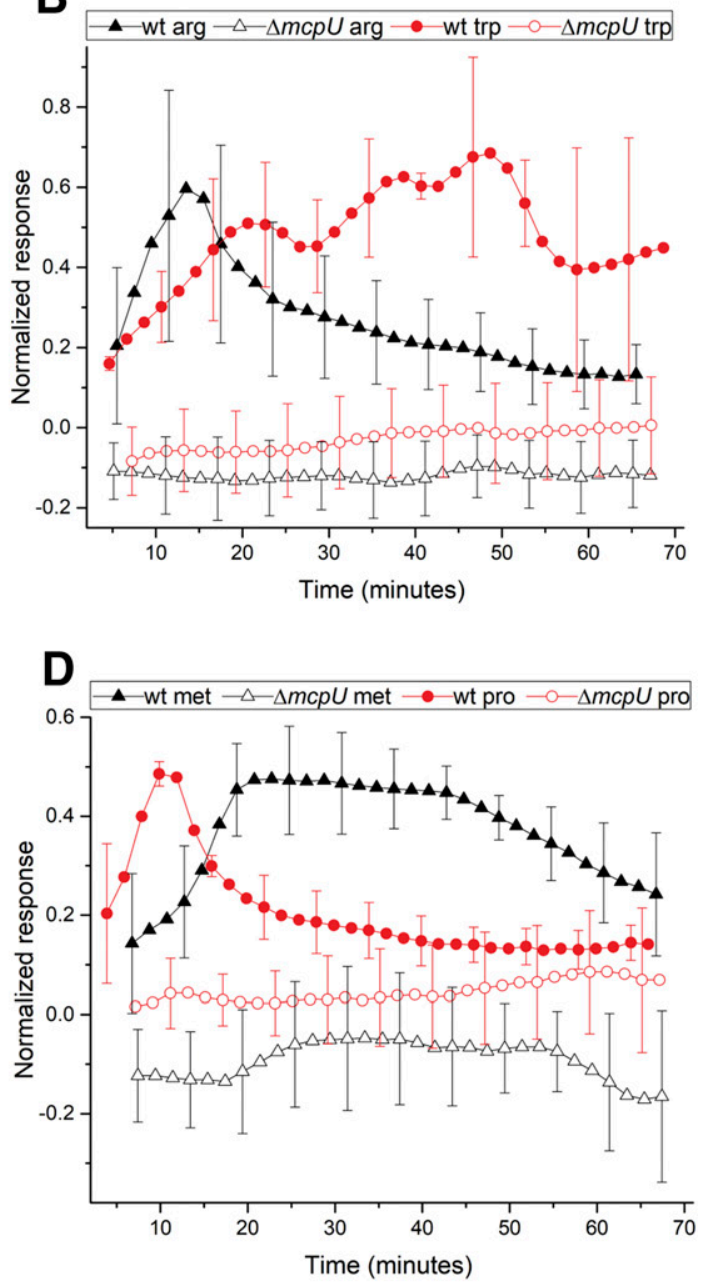

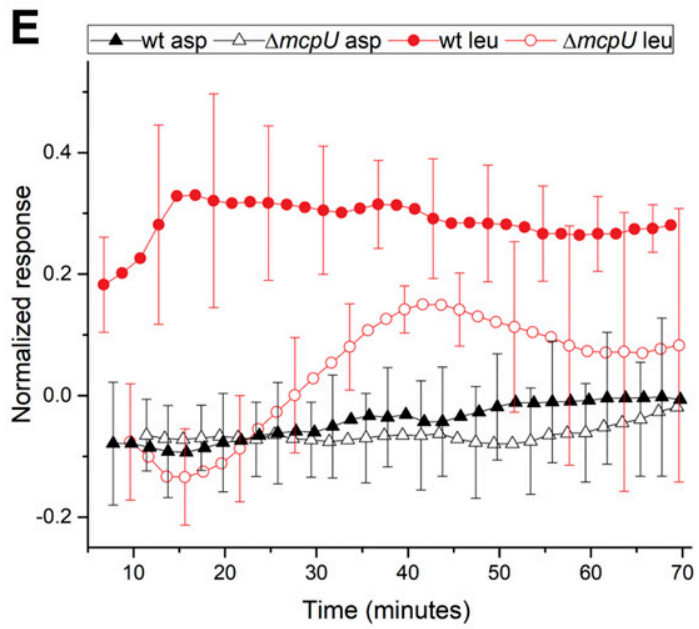

Fig. 4. Chemotaxis responses of Sinorhizobium meliloti wild type and the $\Delta m c p U$ strain to ten representative amino acids at a concentration of $1 \mathrm{mM}$ in the hydrogel capillary assay. Images were taken every $4 \mathrm{~min}$, and the pixel intensities at the mouth of the capillaries were quantified and normalized to the maximum response observed. Black and red circles and triangles denote the wild type and open circles and triangles denote the $m c p U$ deletion strain. A, Responses to histidine and phenylalanine, B, arginine and tryptophan, $\mathbf{C}$, glutamic acid and threonine, D, methionine and proline, E, aspartic acid and leucine. Amino acids are grouped based on best data representation. Values are the means and standard deviations of three biological replicates. For presentation clarity, error bars are presented for every third data point. 
Therefore, aa sensing by McpU most likely occurs in the same ligand-binding pocket. The presence of two negatively charged aa within the binding pocket may explain the lack of interaction of McpU-PR with the acidic aa asp and glu. In addition, we found no direct binding of sugars and most organic acids; however, citric acid was identified as a likely ligand for McpU (Table 1). Interestingly, citric acid has been reported to be one of the most abundant organic acids in alfalfa seed exudates (Lipton et al. 1987). The chemotactic profile of S. meliloti to citric and other organic acids and the contribution of McpU to this response remains to be investigated. Pseudomonas putida possesses three chemoreceptors that sense organic acids including citric acid (Parales et al. 2013), underscoring the importance of organic acid chemotaxis for soil bacteria. Using in-vitro trp binding and trp displacement assays, we confirmed the lack of asp and glu binding to McpU-PR. Therefore, McpU can be placed in the same subfamily of broad-range aa receptors that possess a dual PDC domain structure but do not sense negatively charged aa directly, such as Bacillus subtilis McpC and Pseudomonas syringae PctA (Glekas et al. 2012; McKellar et al. 2015). McpU homologs are present in closely related Ensifer (Tak et al. 2013) and Shinella (Qiu et al. 2016) species as well as in the more distant Pseudomonas citronellolis (Remus-Emsermann et al. 2016). However, the absence of a $m c p U$ gene in the $S$. meliloti GR4 genome indicates that it is not omnipresent in this species.

There appeared to be no strict correlation between the binding affinity and strength of chemotactic responses. The strong attractants phe and trp and the medium attractant pro exhibited comparable binding strengths, while the affinity for the strong attractant arg was 10-fold weaker (Table 2). Therefore, the chemotaxis response of $S$. meliloti is not necessarily reflected in the in vitro binding characteristics. A similar observation was made for the binding of ala and pro to Bacillus subtilis McpC (Glekas et al. 2012), which can be explained by different conformational changes of the receptor and, consequently, signaling to the histidine kinase CheA.

Our previous study identified McpU as the most important chemoreceptor for host sensing (Webb et al. 2016). Here, we classified McpU as a broad-range aa sensor, which also directly interacts with citric acid. Individual aa elicit a broad spectrum

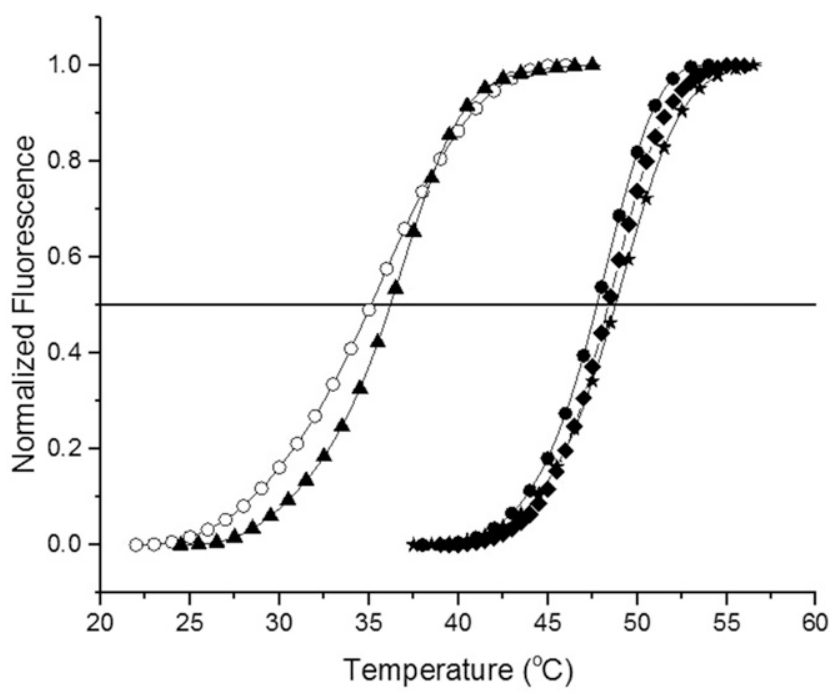

Fig. 5. Differential scanning fluorimetry profiles for binding of representative amino acids (aa) to the periplasmic region of McpU. Protein stability was monitored as a function of fluorescence intensity. Proteins were tested at a concentration of $10 \mu \mathrm{M}$ without $(\bigcirc)$ or with aa, $10 \mathrm{mM}$ arginine (*), $4.3 \mathrm{mM}$ glutamic acid $(\square), 6 \mathrm{mM}$ phenylalanine $(\boldsymbol{\bullet})$, and $10 \mathrm{mM}$ pro $(\diamond)$. The horizontal line represents the melting temperature. of response intensities and times, which aids in survival and host sensing of $S$. meliloti in the soil.

\section{MATERIALS AND METHODS}

Media and growth conditions.

S. meliloti RU11/001 (wild type) (Pleier and Schmitt 1991), RU11/828 ( $\Delta m c p U$ ) (Meier et al. 2007), and RU13/149 (che) (Meier et al. 2007) were grown in TYC $(0.5 \%$ [wt/vol] tryptone, $0.3 \%$ [wt/vol] yeast extract, $0.13 \% \mathrm{CaCl}_{2} \times 6 \mathrm{H}_{2} \mathrm{O}$ [wt/vol], $\mathrm{pH}$ 7.0) and streptomycin $(600 \mu \mathrm{g} / \mathrm{ml})$ at $30^{\circ} \mathrm{C}$ (Platzer et al. 1997). Motile cells for hydrogel capillary assays were grown for 2 days in TYC, were diluted 1:1,000 in $3 \mathrm{ml}$ of TYC, and were grown overnight. Cultures were then diluted 1:1,000 in $10 \mathrm{ml}$ of $\mathrm{RB}\left(6.1 \mathrm{mM} \mathrm{K}_{2} \mathrm{HPO}_{4}, 3.9 \mathrm{mM} \mathrm{KH}{ }_{2} \mathrm{PO}_{4}, 1 \mathrm{mM} \mathrm{MgSO} 4,1 \mathrm{mM}\right.$ $\left[\mathrm{NH}_{4}\right]_{2} \mathrm{SO}_{4}, 0.1 \mathrm{mM} \mathrm{CaCl} 2,0.1 \mathrm{mM} \mathrm{NaCl}, 0.01 \mathrm{mM} \mathrm{Na}_{2} \mathrm{MoO}_{4}$, $0.001 \mathrm{mM} \mathrm{FeSO}_{4}, 20 \mu \mathrm{g}$ of biotin per liter, $10 \mu \mathrm{g}$ of thiamine per liter [Götz et al. 1982]), were layered on Bromfield agar plates with no antibiotics (Sourjik and Schmitt 1996), and were incubated at $30^{\circ} \mathrm{C}$ for approximately $15 \mathrm{~h}$, to an optical density at $600 \mathrm{~nm}\left(\mathrm{OD}_{600}\right)$ of $0.16 \pm 0.02$.

\section{Hydrogel capillary assay.}

Prior to experiments, capillaries containing a cross-linked hydrogel were prepared according to Webb et al. (2016). Stock solution of aa (Fluka analytical kit, 21 L-aa + gly) were dissolved in $\mathrm{RB}$, were adjusted to a final concentration of $1 \mathrm{mM}$ in $\mathrm{RB}$, were sterile filtered, and were stored at $-30^{\circ} \mathrm{C}$. The $\mathrm{pH}$ of all working aa solutions was verified to be 7.0. Hydrogel capillaries were washed and equilibrated for $4 \mathrm{~h}$ twice with RB. Solutions of aa were thawed to room temperature and were briefly vortexed. For equilibration of the capillaries with aa, capillaries were placed into $50 \mu \mathrm{l}$ of aa solution per capillary and were left overnight at $4^{\circ} \mathrm{C}$. Cells were prepared and

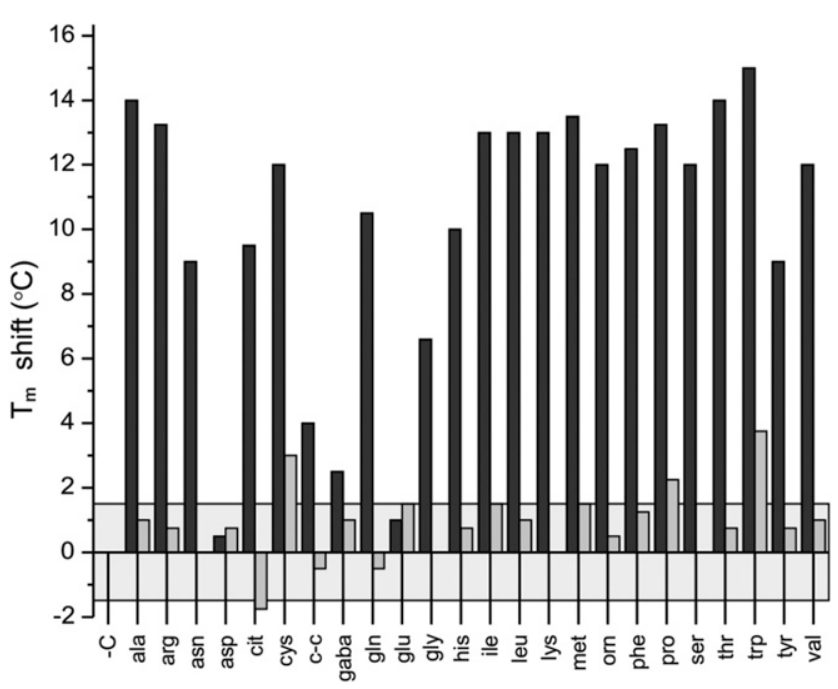

Fig. 6. Interaction of the periplasmic region of $\mathrm{McpU}(\mathrm{McpU}-\mathrm{PR})$ and McpU-PR ${ }^{\text {D182E }}$ with amino acids (aa), determined by differential scanning fluorimetry. Melting temperature $\left(\mathrm{T}_{\mathrm{m}}\right)$ shifts were recorded after subtraction of the negative control. McpU-PR (black) and McpU-PR ${ }^{\mathrm{D} 182 \mathrm{E}}$ (dark gray) were tested at a concentration of $10 \mathrm{vM}$ with or without $10 \mathrm{mM}$ of each aa, with the following exceptions due to solubility limitations: asparagine (asn), $9.4 \mathrm{mM}$; aspartic acid (asp), $4.8 \mathrm{mM}$; cystine (c-c), $0.115 \mathrm{mM}$; glutamic acid (glu), $4.3 \mathrm{mM}$; phenylalanine (phe), $6 \mathrm{mM}$; tryptophan (trp), $5.8 \mathrm{mM}$; and tyrosine (tyr), $0.62 \mathrm{mM}$. Citrulline (cit), ornithine (orn). The horizontal box (light gray) represents the background $\left( \pm 1.5^{\circ} \mathrm{C}\right)$ encompassing the range in fluctuation of fluorescence from the negative control. 
harvested by centrifugation at $4,000 \times g$ for $5 \mathrm{~min}$ at room temperature and were suspended with $\mathrm{RB}$ to an $\mathrm{OD}_{600}$ of 0.12 .

\section{Quantification of chemotaxis responses.}

Quantification of the responses was, essentially, performed according to Webb et al. (2016), with minor modifications. Images from the hydrogel capillary assay were adjusted by rotation to align the capillaries in such a way that the capillaries rest precisely on top of one another when images were stacked. Rotated images were then imported to ImageJ (United States National Institutes of Health) as an image sequence. A rectangular region of interest (ROI) spanning 424 pixels wide and 235 pixels high was placed in front of the mouth of the capillary to encapsulate the chemotactic response and the Time Series Analyzer v3 plugin (J. Balaji, University of California, Los Angeles, U.S.A.) was utilized to attain the average intensity from this ROI (response ROI). To account for background, an ROI with the same dimensions was placed at the top of each image, distant from the chemotactic response (background ROI). The average intensities obtained from the background of each image were subtracted from their respective intensities of the response ROIs. These intensity values were then normalized to the greatest average intensity value observed from the wildtype strain, which was the response to $1 \mathrm{mM}$ arg at $16 \mathrm{~min}$.

\section{Expression and purification}

of the wild type and mutant variant McpU-PR.

The recombinant ligand-binding McpU-PR (McpU $\left.{ }_{40-284}\right)$ and its single aa substitution variant (McpU-PR $\left.{ }^{\mathrm{D} 182 \mathrm{E}}\right)$ were overproduced from plasmid pBS373 and pBS390 (Webb et al. 2014) in Escherichia coli M15/pREP4, providing N-terminal His $_{6}$-tagged proteins. Five liters of each cell culture were grown to an $\mathrm{OD}_{600}$ of 0.8 at $37^{\circ} \mathrm{C}$ in Luria Bertani containing $100 \mu \mathrm{g}$ of ampicillin and $50 \mu \mathrm{g}$ of kanamycin per milliliter, and gene expression was induced by the addition of $0.6 \mathrm{mM}$ isopropyl$\beta$-D-thiogalactopyranoside. Cultivation was continued for $4 \mathrm{~h}$ at $25^{\circ} \mathrm{C}$ until harvest. Cells were suspended in $50 \mathrm{ml}$ of column buffer $(500 \mathrm{mM} \mathrm{NaCl}, 25 \mathrm{mM}$ imidazole, $1 \mathrm{mM}$ phenylmethylsulfonyl fluoride [PMSF], $20 \mathrm{mM} \mathrm{NaPO}_{4}, \mathrm{pH}$ 7.4) and were lysed by three passages through a French pressure cell at 20,000 psi (SLM Aminco, Silver Spring, MD, U.S.A.) and the soluble fraction was loaded onto three stacked 5-ml NTA columns (GE Healthcare Life Sciences, Marlborough, MA, U.S.A.) charged with $\mathrm{Ni}^{2+}$. Protein was eluted from the column with elution buffer $(500 \mathrm{mM} \mathrm{NaCl}, 250 \mathrm{mM}$ imidazole, $1 \mathrm{mM}$ PMSF, $20 \mathrm{mM} \mathrm{NaPO}$, pH 7.0) in a gradient fashion. Pooled fractions were further purified by Äktaprime Plus gel filtration

Table 1. Thermal shift results of the periplasmic region of McpU with various organic acids, inorganic salts, and sugars ${ }^{\mathrm{a}}$

\begin{tabular}{lcll}
\hline Compound & $\boldsymbol{\Delta} \mathbf{T}_{\mathbf{m}}\left({ }^{\circ} \mathbf{C}\right)$ & Compound & $\Delta \mathbf{T}_{\mathbf{m}}\left({ }^{\circ} \mathbf{C}\right)$ \\
\hline Organic acids & & Sugars & \\
Citric acid & 14 & Arabinose & 1.0 \\
Fumaric acid & 0 & Fructose & 0 \\
Glutaronic acid & 0 & Galacturonic acid & 1.5 \\
Itaconic acid & 0 & Glucose & 0 \\
Malic acid & 0 & Maltose & 0 \\
Succinic acid & 0 & Mannose & 0 \\
& & Rhamnose & 0 \\
Inorganic salts & & Ribose & 0 \\
NaCl & 0 & Sucrose & 0.5 \\
$\mathrm{NaNO}_{3}$ & 1.5 & Xylose & 0 \\
$\mathrm{KCl}$ & 0 & & \\
\hline
\end{tabular}

${ }^{a}$ All compounds were tested at final concentrations of 10 and $100 \mathrm{mM}$, with the exception of citric acid, which was tested at $10 \mathrm{mM}$. The sugars are D-enantiomers, glutaronic acid is the D-enantiomer and malic acid is the L-enantiomer. Only maximal temperature shifts are listed. $\mathrm{T}_{\mathrm{m}}=$ melting temperature.
HiPrep 26/60 Sephacryl S-300 HR (GE Healthcare Life Sciences). The column was equilibrated and developed in $100 \mathrm{mM}$ $\mathrm{NaCl}, 50 \mathrm{mM}$ HEPES, $\mathrm{pH} 7.0$, at $0.5 \mathrm{ml} / \mathrm{min}$, and proteincontaining fractions were pooled and concentrated by ultrafiltration, using 10-kDa regenerated cellulose membranes in 50- and 10-ml Amicon filter units (Millipore, Bedford, MA, U.S.A.), and were stored at $4^{\circ} \mathrm{C}$. Protein concentrations were quantified using standard Bradford assays, absorbance at 280 measurements, and total aa analysis after acid hydrolysis.

\section{Thermal denaturation studies.}

DSF experiments were performed essentially as described by Webb et al. (2014), using a Bio-Rad CFX96 realtime system, C1000 thermal cycler in conjunction with Bio-Rad CFX manager software (Life Science Research, Hercules, CA, U.S.A.). Compounds were dissolved in $100 \mathrm{mM} \mathrm{NaCl}, 50 \mathrm{mM}$ HEPES, $\mathrm{pH} 7.0$, and were used at final concentrations of $10 \mathrm{mM}$, unless otherwise stated. McpU-PR or McpU-PR ${ }_{\mathrm{D} 182 \mathrm{E}}$ and SYPRO Orange (Invitrogen, Grand Island, NY, U.S.A.) were diluted in the same buffer to final concentrations of $10 \mu \mathrm{M}$ protein and a final SYPRO Orange concentration of $0.7 \times$ (from $5,000 \times$ stock). Thirty-microliter reactions of all conditions were performed in duplicate. A temperature gradient was applied from 10 to $85^{\circ} \mathrm{C}$ with a $30 \mathrm{~s}$ equilibration at each $0.5^{\circ} \mathrm{C}$. Fluorescence was quantified, using the preset parameters for FRET as the fluorophore and SYBR green as the target. Melting temperatures were recorded and averaged.

\section{Trp displacement assay.}

Trp binding and displacement assays with McpU-PR were performed by an ultracentrifugation method (Sucharitakul et al. 2006), using Amicon Ultra centrifugal filter units (Ultracel $10,000 \mathrm{NMWL})$. Trp binding $(10 \mu \mathrm{M})$ was measured with varying concentrations of McpU-PR ( 0 to $53 \mu \mathrm{M}$ ), and displacement assays were performed with $30 \mu \mathrm{M}$ McpU, $10 \mu \mathrm{M}$ trp, and varying concentrations ( 0 to $1 \mathrm{mM}$ ) of arg, asp, glu, phe, and pro. Each assay solution was incubated for $5 \mathrm{~min}$ at $25^{\circ} \mathrm{C}$ and was centrifuged at $16,873 \times g$ for $15 \mathrm{~min}$ at $4^{\circ} \mathrm{C}$. Concentrations of free and bound trp in the filtrate and retentate, respectively, were determined by fluorescence measurements in a 384-well black plate (Corning 3575BC; Corning, NY, U.S.A.), using an excitation wavelength of $280 \mathrm{~nm}$ and an emission wavelength 355 nm (SpectraMax M5; Molecular Devices, Sunnyvale, CA, U.S.A.). To determine the $\mathrm{K}_{\mathrm{d}}$, the concentration of bound trp was plotted against either the protein or the ligand concentration according to

$$
Y=\frac{B_{\max }[X]}{K_{d}+[X]}
$$

where $X$ and $Y$ represent the concentration of free and bound ligands, respectively, $B_{\max }$ is the maximum specific binding, and $K_{d}$ is the dissociation constant for the ligand.

Table 2. Binding of selected amino acids to the periplasmic region of McpU, determined by fluorescence spectroscopy in competition with tryptophan (trp)

\begin{tabular}{lcc}
\hline Amino acid & $\mathbf{K}_{\mathbf{d}}(\boldsymbol{\mu M})^{\mathbf{a}}$ & Attractant strength \\
\hline Arginine & $350 \pm 140$ & 0.60 \\
Aspartic acid & No binding & 0 \\
Glutamic acid & No binding & 0.10 \\
Phenylalanine & $53 \pm 10$ & 0.85 \\
Proline & $42 \pm 9$ & 0.49 \\
Tryptophan & $34 \pm 8$ & 0.68 \\
\hline
\end{tabular}

${ }^{a}$ Binding was determined in competition with trp via ultracentrifugation and fluorescence measurements of the filtrate and retentate except for trp, which was titrated directly. $\mathrm{K}_{\mathrm{d}}=$ dissociation constant. 


\section{ACKNOWLEDGMENTS}

This study was supported by National Science Foundation grant MCB1253234. We are indebted to B. Behkam for sharing the Zeiss Axio Observer Research microscope and the Omnicure S1000 UV light source, to F. Schubot for sharing the Bio-Rad CFX96 Realtime System, and to T. Arapov, K. Broadway, and R. C. Saldana for critical reading of the manuscript.

\section{LITERATURE CITED}

Althabegoiti, M. J., López-García, S. L., Piccinetti, C., Mongiardini, E. J., Pérez-Giménez, J., Quelas, J. I., Perticari, A., and Lodeiro, A. R. 2008. Strain selection for improvement of Bradyrhizobium japonicum competitiveness for nodulation of soybean. FEMS Microbiol. Lett. 282:115-123.

Ames, P., and Bergman, K. 1981. Competitive advantage provided by bacterial motility in the formation of nodules by Rhizobium meliloti. J. Bacteriol. 148:728-908.

Anantharaman, V., and Aravind, L. 2000. Cache-a signaling domain common to animal $\mathrm{Ca}\left(2^{+}\right)$-channel subunits and a class of prokaryotic chemotaxis receptors. Trends Biochem. Sci. 25:535-537.

Aravind, L., and Ponting, C. P. 1999. The cytoplasmic helical linker domain of receptor histidine kinase and methyl-accepting proteins is common to many prokaryotic signalling proteins. FEMS Microbiol. Lett. 176:111-116.

Barbour, W. M., Hattermann, D. R., and Stacey, G. 1991. Chemotaxis of Bradyrhizobium japonicum to soybean exudates. Appl. Environ. Microbiol. 57:2635-2639.

Bergman, K., Gulash-Hoffee, M., Hovestadt, R. E., Larosiliere, R. C., Ronco, P. G., 2nd, and Su, L. 1988. Physiology of behavioral mutants of Rhizobium meliloti: Evidence for a dual chemotaxis pathway. J. Bacteriol. 170:3249-3254

Bi, S., and Lai, L. 2015. Bacterial chemoreceptors and chemoeffectors. Cell. Mol. Life Sci. 72:691-708.

Caetano-Anollés, G., Wall, L. G., De Micheli, A. T., Macchi, E. M., Bauer, W. D., and Favelukes, G. 1988. Role of motility and chemotaxis in efficiency of nodulation by Rhizobium meliloti. Plant Physiol. 86:1228-1235.

Cooper, J. E. 2007. Early interactions between legumes and rhizobia: Disclosing complexity in a molecular dialogue. J. Appl. Microbiol. 103: 1355-1365.

Dharmatilake, A. J., and Bauer, W. D. 1992. Chemotaxis of Rhizobium meliloti towards nodulation gene-inducing compounds from alfalfa roots. Appl. Environ. Microbiol. 58:1153-1158.

Dunn, M. F. 2015. Key roles of microsymbiont amino acid metabolism in rhizobia-legume interactions. Crit. Rev. Microbiol. 41:411-451.

Gaworzewska, E. T., and Carlile, M. J. 1982. Positive chemotaxis of Rhizobium leguminosarum and other bacteria towards root exudates from legumes and other plants. J. Gen. Microbiol. 128:1179-1188.

Glekas, G. D., Mulhern, B. J., Kroc, A., Duelfer, K. A., Lei, V., Rao, C. V., and Ordal, G. W. 2012. The Bacillus subtilis chemoreceptor McpC senses multiple ligands using two discrete mechanisms. J. Biol. Chem. 287:39412-39418.

Götz, R., Limmer, N., Ober, K., and Schmitt, R. 1982. Motility and chemotaxis in two strains of Rhizobium with complex flagella. J. Gen. Microbiol. 128:789-798.

Hazelbauer, G. L., Falke, J. J., and Parkinson, J. S. 2008. Bacterial chemoreceptors: High-performance signaling in networked arrays. Trends Biochem. Sci. 33:9-19.

Hirsch, A. M., Lum, M. R., and Downie, J. A. 2001. What makes the rhizobia-legume symbiosis so special? Plant Physiol. 127:1484-1492.

Jones, K. M., Kobayashi, H., Davies, B. W., Taga, M. E., and Walker, G. C. 2007. How rhizobial symbionts invade plants: The SinorhizobiumMedicago model. Nat. Rev. Microbiol. 5:619-633.

Lipton, D. S., Blanchar, R. W., and Blevins, D. G. 1987. Citrate, malate, and succinate concentration in exudates from P-sufficient and P-stressed Medicago sativa $\mathrm{L}$. seedlings. Plant Physiol. 85:315-317.

Malek, W. 1989. Chemotaxis in Rhizobium meliloti strain L5.30. Arch. Microbiol. 152:611-612.

McKellar, J. L., Minnell, J. J., and Gerth, M. L. 2015. A high-throughput screen for ligand binding reveals the specificities of three amino acid chemoreceptors from Pseudomonas syringae pv. actinidiae. Mol. Microbiol. 96:694-707.

Meier, V. M., Muschler, P., and Scharf, B. E. 2007. Functional analysis of nine putative chemoreceptor proteins in Sinorhizobium meliloti. J. Bacteriol. 189:1816-1826.
Mellor, H. Y., Glenn, A. R., Arwas, R., and Dilworth, M. J. 1987. Symbiotic and competitive properties of motility mutants of Rhizobium trifolii Ta1. Arch. Microbiol. 148:34-39.

Mesibov, R., and Adler, J. 1972. Chemotaxis toward amino acids in Escherichia coli. J. Bacteriol. 112:315-326.

Miller, L. D., Yost, C. K., Hynes, M. F., and Alexandre, G. 2007. The major chemotaxis gene cluster of Rhizobium leguminosarum bv. viciae is essential for competitive nodulation. Mol. Microbiol. 63:348-362.

Nelson, E. B. 2004. Microbial dynamics and interactions in the spermosphere. Annu. Rev. Phytopathol. 42:271-309.

Niesen, F. H., Berglund, H., and Vedadi, M. 2007. The use of differential scanning fluorimetry to detect ligand interactions that promote protein stability. Nat. Protoc. 2:2212-2221.

Parales, R. E., Luu, R. A., Chen, G. Y., Liu, X., Wu, V., Lin, P., Hughes, J. G., Nesteryuk, V., Parales, J. V., and Ditty, J. L. 2013. Pseudomonas putida F1 has multiple chemoreceptors with overlapping specificity for organic acids. Microbiology 159:1086-1096.

Platzer, J., Sterr, W., Hausmann, M., and Schmitt, R. 1997. Three genes of a motility operon and their role in flagellar rotary speed variation in Rhizobium meliloti. J. Bacteriol. 179:6391-6399.

Pleier, E., and Schmitt, R. 1991. Expression of two Rhizobium meliloti flagellin genes and their contribution to the complex filament structure. J. Bacteriol. 173:2077-2085.

Qiu, J., Yang, Y., Zhang, J., Wang, H., Ma, Y., He, J., and Lu, Z. 2016. The complete genome sequence of the nicotine-degrading bacterium Shinella sp. HZN7. Front. Microbiol. 7:1348.

Remus-Emsermann, M. N., Schmid, M., Gekenidis, M. T., Pelludat, C., Frey, J. E., Ahrens, C. H., and Drissner, D. 2016. Complete genome sequence of Pseudomonas citronellolis P3B5, a candidate for microbial phylloremediation of hydrocarbon-contaminated sites. Stand. Genomic Sci. 11:75.

Reyes-Darias, J. A., Yang, Y., Sourjik, V., and Krell, T. 2015. Correlation between signal input and output in PctA and PctB amino acid chemoreceptor of Pseudomonas aeruginosa. Mol. Microbiol. 96:513-525.

Scharf, B. E., Hynes, M. F., and Alexandre, G. M. 2016. Chemotaxis signaling systems in model beneficial plant-bacteria associations. Plant Mol. Biol. 90:549-559.

Soby, S., and Bergman, K. 1983. Motility and chemotaxis of Rhizobium meliloti in soil. Appl. Environ. Microbiol. 46:995-998.

Sourjik, V., and Schmitt, R. 1996. Different roles of CheY1 and CheY2 in the chemotaxis of Rhizobium meliloti. Mol. Microbiol. 22:427-436.

Sucharitakul, J., Chaiyen, P., Entsch, B., and Ballou, D. P. 2006. Kinetic mechanisms of the oxygenase from a two-component enzyme, p-hydroxyphenylacetate 3-hydroxylase from Acinetobacter baumannii. J. Biol. Chem. 281:17044-17053.

Suzaki, T., Yoro, E., and Kawaguchi, M. 2015. Leguminous plants: Inventors of root nodules to accommodate symbiotic bacteria. Int. Rev. Cell Mol. Biol. 316:111-158.

Tak, N., Gehlot, H. S., Kaushik, M., Choudhary, S., Tiwari, R., Tian, R., Hill, Y., Bräu, L., Goodwin, L., Han, J., Liolios, K., Huntemann, M., Palaniappan, K., Pati, A., Mavromatis, K., Ivanova, N., Markowitz, V., Woyke, T., Kyrpides, N., and Reeve, W. 2013. Genome sequence of Ensifer sp. TW10; a Tephrosia wallichii (Biyani) microsymbiont native to the Indian Thar Desert. Stand. Genomic Sci. 9:304-314.

Ulrich, L. E., and Zhulin, I. B. 2005. Four-helix bundle: A ubiquitous sensory module in prokaryotic signal transduction. Bioinformatics 21 (Suppl 3):iii45-iii48.

Uren, N. C. 2000. Types, amounts and possible functions of compounds released into the rhizosphere by soil-grown plants. Pages 19-40 in: The Rhizosphere: Biochemistry and Organic Substances at the Soil-Plant Interface. R. Pinton, Z. Varanini, and P. Nannipiero, eds. CRC Press, New York.

Webb, B. A., Helm, R. F., and Scharf, B. E. 2016. Contribution of individual chemoreceptors to Sinorhizobium meliloti chemotaxis towards amino acids of host and nonhost seed exudates. Mol. Plant-Microbe Interact 29:231-239.

Webb, B. A., Hildreth, S., Helm, R. F., and Scharf, B. E. 2014. Sinorhizobium meliloti chemoreceptor McpU mediates chemotaxis toward host plant exudates through direct proline sensing. Appl. Environ. Microbiol. 80:3404-3415.

\section{AUTHOR-RECOMMENDED INTERNET RESOURCES}

United States National Institutes of Health Image J software: https://imagej.nih.gov/ij

Time Series Analyzer version 3.0 software: https://imagej.nih.gov/ij/plugins/time-series.html 